Journal of Epidemiology and Community Health, 1989, 43, 103-106

Review Article

\title{
Screening for cancer of the cervix
}

\author{
N E DAY \\ From the MRC Biostatistics Unit, 5 Shaftesbury Road, Cambridge CB2 $2 B W$
}

Mortality from cancer of the cervix can be reduced greatly by cytological screening. Unfortunately, women in this country have benefited little, and for a country whose health service should excel at preventive medicine, the results have been particularly disappointing. This is the result of a lack of a clear focus of responsibility. To be effective, screening needs a continuous emphasis on quality in a setting which is apparently routine and mundane. Where in the health service are the rewards for quality? The basis for a policy for effective screening can be found in the organisation of programmes which have produced results, and in the underlying natural history of the disease.

The potential of mass screening for cancer of the cervix to reduce morbidity and mortality from the disease is now acknowledged. However, even though screening was introduced some 30 years ago in some countries, conclusive evidence of its effectiveness has been slow to appear. This delay was the direct result of enthusiasm running ahead of critical appraisal, so that the randomised trials that could have settled the issue in the early 1960s were never performed. This is in stark contrast with breast screening, where there is now more conclusive evidence of benefit from a procedure which is much less effective in reducing death and morbidity from advanced disease. The most persuasive evidence that screening for cervical cancer is effective comes from comparisons of time trends in populations which introduced mass screening with different intensities and at different times. The numerous studies based on the analysis of individual cases have of course addressed the issue of effectiveness, but have been more informative about the relative benefit of different screening policies.

The Nordic countries have provided the clearest data. The five countries, with uniformly high levels of medical care, adopted very different policies towards screening and have shown sharply contrasting trends both in incidence ${ }^{1}$ and in mortality ${ }^{2}$ from cervical cancer since the mid-1960s, when mass screening started. Mortality is the most conclusive end point to consider. Table 1 gives the change in mortality in different age groups over the period from before the time when screening could have influenced mortality, ie $1963-67$, to the time when the full effect should have been revealed (1978-82).

The relationship between the degree of reduction in mortality and the extent of mass screening for women over $\mathbf{4 0}$ is striking. Because these are not the results of

Table 1 Change (\%) in mortality from cervical cancer between $1963-67$ and 1978-82 in the Nordic countries, by age group.

\begin{tabular}{|c|c|c|c|c|c|c|}
\hline & \multirow{2}{*}{$\begin{array}{l}\text { Overall age group } \\
\text { covered (years) }\end{array}$} & \multirow{2}{*}{$\begin{array}{l}\% \text { target age group } \\
\text { covered nationally }\end{array}$} & \multicolumn{4}{|c|}{ Change in mortality (\%) by age group } \\
\hline & & & $30-39$ & $40-49$ & $50-59$ & $60-69$ \\
\hline Iceland & $25-69$ & 80 & -100 & -77 & -66 & -66 \\
\hline Finland & $30-55$ & 75 & -72 & -77 & -60 & -32 \\
\hline Sweden & $30-49$ & 70 & -59 & -63 & -40 & +7 \\
\hline Denmark & $30-50$ & 35 & -61 & -53 & -26 & +1 \\
\hline Norway & $25-60$ & 3 & -48 & -23 & -2 & +14 \\
\hline
\end{tabular}


randomised trials, it is always possible to propose alternative explanations, but the straightforward interpretation is that the different changes in mortality are due to the different levels of organised screening. This relates to women over 40 years of age. Below 40 , there is little relationship between the level of organised screening and the change in cervical cancer mortality, since it is in these younger age groups that opportunistic screening, related to pregnancy and contraception, is very widespread. The relationship between organised and opportunistic screening will be discussed later, but it is clear from table 1 that opportunistic screening does not reach many women over the age of 40 . In Iceland, ${ }^{3}$ where information on stage is available on a population basis, the major changes in incidence following the introduction of screening refer to stage II or worse, that is the advanced cancers.

The success of organised screening programmes in the Nordic countries and elsewhere, for example north-east Scotland, ${ }^{4}$ has not led to an overall consensus on how screening should be organised, or even perhaps on what constitutes its major aim. Prevention of invasive disease is achieved by detection and treatment of pre-invasive lesions, but the potential of the latter for progression to invasion is highly variable. If the aim of screening is taken to be the detection of pre-invasive disease without taking account of this variability, the primary target of preventing invasive cancers will be blurred. The two questions with which one might begin to construct an approach to screening are: (1) At what age does the condition to be prevented, ie, invasive cancer, occur? and (2) How long before the onset of this condition can treatable precursor conditions be recognised? A subsidiary question to the latter refers to the accuracy of the test used for detecting this precursor.

The age at which invasive cervical cancer appears is of course well known, but in the context of screening it is worth stressing again. In populations where screening has had little effect, the pattern of incidence with age follows a similar course whether the disease is very common or relatively rare. One can compare Cali in Colombia with the West Midland region in the UK for the late $1960 \mathrm{~s}^{5}$ The disease is about five times more common in Cali, and this ratio is seen in each age group. Rates per $10^{5}$ population per year, by 5 year age group, are given in table 2. Irrespective of whether the disease is rare or common, the incidence rises rapidly with age until about 40 years, and then levels off. The level of this plateau is 20 -fold or more higher than the average incidence seen in the 20-29 age group; in the under $25 \mathrm{~s}$, the disease is very rare in both populations. Cervical cancer is more common now in younger women in this country, but there is no indication at all that rates will surpass those seen earlier in Cali, or that the disease occurs earlier.

The answer to the second question, the length of time during which precursor lesions are detectable before invasive cancer occurs, was for a long time obscure. The issue was confused by an overconcentration on the natural history of precursor lesions detected at screening. As is now clear, a great many of these lesions, particularly mild or moderate karyosis in younger women, will not progress, and will in fact regress. ${ }^{6}$ The natural history of these lesions is important for determining how they should be treated, but is less relevant to the risk of invasion. For this, one has to consider the rapidity with which an invasive lesion can arise from an epithelium which had given at normal cytological smear. This again is an issue fop which randomised trials could have provided clear and unequivocal results, but the information can be extracted from ongoing screening programmes. $A-\overrightarrow{-}$ large number of such programmes have reporte $c$ results, using either a case-control or a cohort study design, and many of these were included in an overview published by the International Agency fof Research on Cancer in $1986 . .^{78}$ The organised programmes included in this overview gave a consistent picture, summarised in table 3 . The results in this table provide the theoretical basis of screening for cervical cancer, defining statistically the window in which precursors can be caught.

The incidence of invasive cancers among women who have had a negative smear, and more specifically, at least two negative smears, returns to the rate in unscreened women about 10 years after the last negative smear. The protection afforded by screening, high in the first 3-5 years, has virtually disappeared after 10 years. From these results, the value of a screening test is in essence to protect against invasive disease occuring in the next 5 years. One can then see from the basic pattern of incidence rates (table 2) that

Table 2 The incidence (rate per $10^{5}$ ) of cervical cancer in high and low risk unscreened populations

\begin{tabular}{|c|c|c|c|c|c|c|c|c|c|c|}
\hline & \multirow{2}{*}{$\begin{array}{l}\text { Age } \\
\text { standardised } \\
\text { rate }\end{array}$} & \multicolumn{9}{|c|}{ Age group (years) } \\
\hline & & $20-24$ & $25-29$ & $30-34$ & $35-39$ & $40-44$ & $45-49$ & $50-54$ & $55-59$ & $60-64$ \\
\hline Cali, Colombia 1963-67 & $75 \cdot 6$ & $4 \cdot 3$ & $15 \cdot 4$ & $47 \cdot 9$ & $98 \cdot 8$ & $154 \cdot 5$ & 191.4 & $186 \cdot 2$ & 236.9 & $277 \cdot 0$ \\
\hline Birmingham, UK 1963-67 & 13.6 & 0.7 & $2 \cdot 8$ & $8 \cdot 7$ & $24 \cdot 6$ & $38 \cdot 5$ & $41 \cdot 7$ & $37 \cdot 7$ & $33 \cdot 1$ & $27 \cdot 1$ \\
\hline
\end{tabular}


Table 3 Incidence rate of invasive squamous carcinoma of the cervix following a negative cytology smear, as a proportion of the incidence in a comparable unscreened population

\begin{tabular}{lc}
\hline $\begin{array}{l}\text { Time since last smear } \\
\text { (months) }\end{array}$ & Proportional incidence \\
\hline $0-11$ & 0.06 \\
$12-23$ & 0.08 \\
$24-35$ & 0.12 \\
$36-47$ & 0.19 \\
$48-59$ & 0.36 \\
$60-71$ & 0.28 \\
$72-119$ & 0.63 \\
$120+$ & -1.0 \\
\hline
\end{tabular}

a smear taken between 35 and 60 years is some 30 -fold more effective in detecting a lesion destined later to become invasive than a smear taken at 20 , and about 10-fold more effective than a smear taken at 25 .

One can use the results of table 3 to predict the results of different screening policies, some of which are shown in table 4 . Compliance of some $80 \%$, with screening every 3-5 years, should give an overall reduction in mortality of 65 to $70 \%$, much as seen in table 1 for some of the Nordic countries. It is clear from these figures that the issue of screening frequency has been given exaggerated importance in the past. Any interval of 5 years or less is going to yield major public health returns. An individual woman might prefer the marginal increase in security associated with yearly (as opposed to 3 yearly) screening, but a health service should be able to find more effective use of its resources.

The predictions of table 4 will only be realised if abnormalities found at screening are prevented from developing into invasive cancers. Their treatment will depend on the assumption one makes on their natural history. Adequate treatment of lesions which would progress is of course essential; overtreatment of lesions which would not progress is one of the costs of screening. From the age pattern of the incidence of invasive cancer, and the results of table 3 , it is evident that most cytological abnormalities detected in young women will not progress. Markers predicting

Table 4 The effectiveness of different screening policies: proportionate reduction in incidence assuming $100 \%$ compliance, based on table 3.

\begin{tabular}{|c|c|c|}
\hline Policy & $\begin{array}{l}\% \text { reduction in cumulative } \\
\text { rate in age group }\end{array}$ & $\begin{array}{l}\text { number of } \\
\text { tests }\end{array}$ \\
\hline Every 10 years $25-64$ & $64 \cdot 0$ & 5 \\
\hline Every 5 years $35-64$ & $69 \cdot 6$ & 6 \\
\hline Every 5 years $25-64$ & 81.8 & 8 \\
\hline Every 5 years $20-64$ & 83.8 & 9 \\
\hline Every 3 years $35-64$ & 77.6 & 10 \\
\hline Every 3 years $25-64$ & 89.8 & 13 \\
\hline Every 3 years $20-64$ & $91 \cdot 2$ & 15 \\
\hline Every year $20-64$ & $93 \cdot 3$ & 35 \\
\hline
\end{tabular}

progression may develop from current work on the human papilloma virus, and would be invaluable. In their absence, clinical decisions have to be made, steering a course between overtreating nonprogressive lesions and undertreating progressive ones. Several programmes have shown that follow up by cytology is effective, provided that the repeat smears can be assured and the cytology is of high quality. The attraction of this policy is that it avoids the high cost of automatic referral to colposcopy. More needs to be known, however, about the risk of progression to invasion, and the factors which influence this risk for the varying degrees of cytological abnormality.

It is clear from the success of cervical cancer screening in Scandinavia and parts of Scotland, and its failure in much of the rest of Britain, that the crucial question is one of organisation, to ensure high compliance and adequate follow up of cytological abnormalities. Leaving screening to the hazards of encounters between individual women and the medical profession leads in general to large numbers of smears being taken from the wrong women, and too few smears from the right women. Screening works best when centrally organised, with individual invitations to participate to each woman in a well defined target population. Once such a system is operating efficiently, there is no real need to stretch limited resources by accommodating opportunistic screening as well. District cytopathology laboratories which refuse such smears are doing the population of their district a service. To ensure that women receive invitations, one needs a population list. It is an astonishing aspect of this country's health service that those responsible for preventive medicine do not have an adequate list of the population giving age and sex, and equally astonishing, that the lists which do exist are only for administrative purposes, for use by those with no medical responsibilities. Transfer of these lists to those who could use them for public health purposes was until recently discouraged. What is not surprising about these Family Practitioner Committee lists, given their use, is their inaccuracy.

Even now, however, when the need for good call/recall systems is sufficiently visible to have become a political issue, the emphasis has been on details of the system rather than on results. Computerisation of the files of the Family Practitioner Committee, and giving it the mandate to run call/recall systems, is no guarantee that women will be screened, especially since the Committees will be merging with or trying to replace a wide array of ad hoc systems, some of which work satisfactorily, that have become established over the years. The computer hardware and software is not the problem. There are thousands of teenagers up and down the country who could write an adequate 
software package for a machine costing $£ 2500$ or so, which any cytopathology laboratory or general practice could install. The issue is one of responsibility: either the director of the district cytopathology laboratory, or a designated community physician, or even each general practice, should be accountable for effective screening. With responsibility, they would need to be given the necessary resources, among which would be accurate lists of the population to be served. One would then expect to see direct indicators, produced routinely, of how the programme was functioning. These would include the proportion of women in the target age range who had not been screened in the previous 5, or 3, years; the number of women with different degrees of cytological abnormality diagnosed, with the different actions taken; and the number of cervical cancer cases diagnosed, tabulated by previous screening history. More succinctly, perhaps, one could propose a screening index. Given the age structure of the female population and the screening history of each woman, one could calculate, based on the quantities in table 2 and 3, the proportionate reduction in cervical cancer incidence that the screening programme should have brought about. This estimated reduction is a direct measure of the effectiveness of the screening, providing a clear quantitative summary of the screening activity in a given population. Statistical monitoring on these lines is an essential part of cervical cancer control.

\section{References}

${ }^{1}$ Hakama M. Trends in the incidence of cervical cancer in the Nordic countries. In: Magnus K, ed. Trends in cancer incidence. New York: Hemisphere, 1982.

${ }^{2}$ Laara E, Day NE, Hakama M. Trends in the mortality from cervical cancer in the Nordic countries in association with organised screening programmes. Lancet 1987; i: 1247-9.

${ }^{3}$ Johannesson G, Geirsson G, Day NE, Tulinius H. Screening for cancer of the uterine cervix in Iceland 1965-78. Acta Obstet Gynecol Scand 1982; 61: 199-203.

${ }^{4}$ MacGregor JE, Moss S, Parkin DM, Day NE. Cervical cancer screening in north-east Scotland. In: Hakama $\mathbf{M}$, Miller AB, Day NE, eds. Screening for cancer of the uterine cervix (IARC Scientific Publications No 76) Lyon: International Agency for Research on Cancer, 1986.

${ }^{5}$ Doll R, Muir C, Waterhouse J. Cancer incidence in five continents, Vol 2. Berlin: UICC, Springer-Verlag, 1970

${ }^{6}$ Boyes DA, Morrison, Knox EG, Draper GJ, Miller AB. A cohort study of cervical cancer screening in British Columbia. Clin Invest Med 1982; 5: 1-29.

${ }^{7}$ Hakama M, Miller AB, Day NE, eds. Screening for cancer of the uterine cervix (IARC Scientific Publications No 76). Lyon: International Agency for Research on Cancer, 1986.

${ }^{8}$ IARC Working Group. Screening for squamous cervica cancer-the duration of low risk following negative cervical cytology and its implication for screening policies. $\mathrm{Br} M e d J$ 1986; 292: 659-64.

Accepted for publication January 1989 